\title{
古尔班通古特沙漠白梭梭枝干光合及其影响因素
}

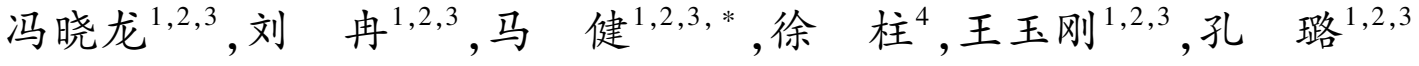 \\ 1 中国科学院新疆生态与地理研究所, 荒漠与绿洲生态国家重点实验室, 乌鲁木齐 830011 \\ 2 中国科学院皁康荒漠生态国家野外科学观测研究站,阜康 831505 \\ 3 中国科学院大学, 北京 100049 \\ 4 新疆天池管理委员会博格达生态环境监测站, 阜康 831500
}

摘要:植物枝干光合 $\left(P_{g}\right)$ 固定其自身呼吸所释放的 $\mathrm{CO}_{2}$, 有效减少植物向大气的 $\mathrm{CO}_{2}$ 排放量。以古尔班通古特沙漠优势木本植 物白梭梭 (Haloxylon persicum) 为研究对象, 利用 LI-COR 6400 便携式光合仪与特制光合叶室(P-Chamber) 相结合, 观测白梭梭叶 片、不同径级枝干的光响应及光合日变化特征; 同时监测环境因子 (大气温湿度、光合有效辐射、土壤温度及含水量等) 与叶片/ 枝干性状指标 (叶绿素含量、含水量、干物质含量、碳/氮含量等), 揭示叶片/枝干光合的主要影响因子; 采用破坏性取样, 量化 个体水平上叶片与枝干的总表面积,阐明枝干光合对植株个体碳平衡的贡献。研究结果显示: (1) 白梭梭叶片叶绿素含量是枝 干叶绿素含量的 12-16 倍,各径级枝干叶绿素含量差异不显著; (2) 枝干光饱和点低于叶片,枝干不同径级 (由粗至细), 暗呼 吸速率和枝干光合逐渐减小; (3) 光合有效辐射、土壤含水量和空气温湿度是影响叶片光合的主要因子,对枝干光合无显著影 响; (4) 枝干光合可以固定其自身呼吸产生 $\mathrm{CO}_{2}$ 的 $73 \%$, 最高可达 $90 \%$, 枝干光合固定 $\mathrm{CO}_{2}$ 约占个体水平固碳量的 $15.4 \%$ 。研究 结果表明,忽视枝干光合的贡献来预测未来气候变化背景下荒漠生态系统碳过程, 可能存在根本性缺陷, 并且在估算枝干呼吸 时,需要考虑枝干是否存在光合作用,以提高枝干呼吸的准确性。

关键词: 枝干光合;皮层光合作用;树皮光合;枝干呼吸;叶绿素含量; 白梭梭

\section{Photosynthetic characteristics and influencing factors of Haloxylon persicum stems (different diameter classes) in Gurbantonggut desert}

\author{
FENG Xiaolong ${ }^{1,2,3}$, LIU Ran ${ }^{1,2,3}$, MA Jian ${ }^{1,2,3, *}$, XU Zhu ${ }^{4}$, WANG Yugang ${ }^{1,2,3}$, KONG Lu ${ }^{1,2,3}$ \\ 1 State Key Laboratory of Desert and Oasis Ecology, Xinjiang Institute of Ecology and Geography, Chinese Academy of Sciences, Urumqi 830011, China \\ 2 Fukang Station of Desert Ecology, Chinese Academy of Sciences, Fukang 831505, China \\ 3 University of China Academy of Sciences, Beijing 100049, China \\ 4 Bogda Ecoenvironmental Station in Tianchi Management Committee, Fukang 831500, China
}

\begin{abstract}
Stem photosynthesis reassimilates $\mathrm{CO}_{2}$ that released from their own respiration, which effectively reduces the $\mathrm{CO}_{2}$ efflux to the atmosphere. In this study, Haloxylon persicum, the dominant woody plant in Gurbantunggut Desert, was selected as the research object. A portable LI- 6400 photosynthesis system combined with P-Chamber was used to observe the light response and diurnal photosynthetic characteristics of leaves and stems. The environmental factors, including temperature and humidity, photosynthetically active radiation, soil temperature and water content, and leaf or stem traits ( chlorophyll content, water content, dry matter content, carbon or nitrogen content, etc.) were monitored to reveal the main influencing factors of leaf or stem photosynthesis. The destructive sampling was used to quantify the total surface area

基金项目:国家自然科学基金项目 (41771121,U1903301); 中国科学院“西部之光-西部青年学者”项目(2020-XBQNXZ-013); “天山雪松计划”-青 年拔尖人才后备人选(2019XS11)

收稿日期: 2020-12-14; 网络出版日期: 2021-08-04

* 通讯作者 Corresponding author.E-mail: majian@ms.xjb.ac.cn
\end{abstract}

http : //www.ecologica.cn 
of leaves and stems to clarify the contribution of stem photosynthesis to individual carbon balance. The results showed that: (1) the chlorophyll content of the leaves was 12-16 times than that of stems in $H$. persicum, and there was no significant difference in chlorophyll content among different diameter stems. (2) The light saturation point of the stems was lower than that of the leaves, and the dark respiration rate and photosynthesis of different diameter classes (from coarse to fine) of stems gradually decreased. (3) The photosynthetic effective radiation, soil moisture and air temperature and humidity were the main factors affecting leaf photosynthesis, but had no significant effect on stem photosynthesis. There was a strong correlation between stem photosynthesis and stem. (4) Stem photosynthesis fixed $73 \%$ of $\mathrm{CO}_{2}$ produced by its own respiration, and the highest rate reached $90 \%$, photosynthetic $\mathrm{CO}_{2}$ fixation in stems accounted for about $15.4 \%$ of individual level carbon fixation. The results of this study show that there may be a fundamental defect in ignoring the contribution of stem photosynthesis to predict the carbon process of desert ecosystem under the background of future climate change. When estimating the stem respiration, it is necessary to consider whether there is stem photosynthesis to improve the accuracy of branch respiration.

Key Words: stem photosynthesis; cortex photosynthesis; bark photosynthesis; stem respiration; chlorophyll content; Haloxylon persicum

叶片是众多陆生植物最主要的光合器官, 此外, 植物的其他部位, 如茎干、花、果实和根系也存在光合作 用 ${ }^{[1]}$ 。因为植物枝干部位的叶绿素主要存在于皮层, 枝干的光合作用又称做皮层光合作用,此外, 叶绿素叶 也存在于木射线和木髓中, 因此也称其为木质组织光合 ${ }^{[2-3]}$ 。枝干光合 $P_{g}$ 通常指利用树皮内的绿色组织, 将 木质组织呼吸产生的 $\mathrm{CO}_{2}$ 重新同化, 也有少数植物茎部, 可以通过气孔吸收部分外界 $\mathrm{CO}_{2}$ 作为底物进行光合 作用 ${ }^{[4]}$ 。

枝干光合 $\left(P_{g}\right)$ 可以作为叶片光合的重要补充, 相较于叶片光合, 枝干光合存在诸多优势。枝干存在时间 较长, 几乎常年存在, 而且在一些小叶物种中, 枝干面积占比较大 ${ }^{[5]}$; 枝干光合 $P_{g}$ 能够提升皮层氧气浓度, 消 除植物茎部暂时性缺氧可能带来的危害 ${ }^{[6]}$; 一般而言, 植物通过光合作用固定的碳中, 有一半通过呼吸返回 到大气中, 而枝干光合可再固定茎部 $\mathrm{CO}_{2}$ 释放量的 $7 \%-123 \%{ }^{[4]}$, 从而有效减少碳的局部损失, 提升植物的水 分利用效率 $(\mathrm{WUE})^{[7-8]}$; 枝干光合也能够影响植物体其他部位的生理活动, Saveyn 等 $^{[2]}$ 对茎部的遮光实验表 明枝干光合有利于枝干生长和幼芽的萌发; Kocurek 等 ${ }^{[9]}$ 对书带木 (Clusia minor) 的研究发现枝干光合可以改 变植物体碳分配, 影响根的生长。干旱胁迫下, 叶片同化和篮管运输受到限制, 而枝干光合产物可视为碳水化 合物的可靠来源 ${ }^{[10]}$, 同时枝干光合可以驱动树皮吸水以修复栓塞, 维持植株的碳平衡和水力结构的完整, 延 迟干旱胁迫 ${ }^{[10-12]}$, 此外, 枝干光合也影响叶片对干旱胁迫的敏感性, 剔除枝干光合的植株中, 叶片最大净光合 速率下降更快 ${ }^{[13]}$ 。

目前已有较多关于植物枝干光合作用的影响因子及其作用机理的研究,但其在不同物种间存在差异。全 球变暖使得树木死亡的可能性升高 ${ }^{[14]}$, 生态学家和植物学家广泛研究干旱胁迫下的植物生理生态响应机制, 植物枝干光合 $P_{g}$ 也引起了广泛关注 ${ }^{[15-17]}$ 。有研究发现西方白松 (Pinus monticolaDougl. ex D. Don) 枝干光合 随温度的升高而持续增加, 最高温度甚至达到 $45^{\circ} \mathrm{C}^{[18]}$ 。除温度外, 其他环境影响因子也引起生态学家的关 注, 臭氧胁迫下,桦树 (Betula pendula Roth.) 叶片光合速率明显下降, 而枝干光合 $\left(P_{g}\right)$ 增加, 枝干光合支撑起 枝干甚至整棵植株的碳平衡 ${ }^{[19]}$ 。刘俊祥等 ${ }^{[20]}$ 对旱柳 (Salix matsudana) 枝干光合的研究表明,枝条不同组织 的光合色素含量和光化学效率呈现随径向深度的增加而显著降低的规律。综上所述, 枝干光合能够帮助维持 植株生理平衡, 在干旱胁迫下发挥重要作用 ${ }^{[21-22]}$, 因此, 对我国干旱区荒漠植物枝干光合的研究, 可以为全球 气候变化背景下荒漠生态系统结构和功能对干旱胁迫的响应提供科学参考。

白梭梭是古尔班通古特沙漠的优势木本植物, 以其作为建群种形成的白梭梭群落是沙漠中分布最广、最 
重要的一个群落,通常出现在流动、半流动和半固定沙地的沙丘顶部和丘坡中上部,在丘坡下部和丘间低地常 被梭梭群落所更替 ${ }^{[23]}$ 。目前对白梭梭叶片和根部特性的研究较多 ${ }^{[24-25]}$, 而枝干光合 $\left(P_{g}\right)$ 特性的研究十分有 限。本试验以白梭梭为研究对象, 阐明白梭梭不同径级枝干光响应与光合日变化特征, 确定最适白梭梭的枝 干光响应曲线拟合模型; 比较枝干与叶片的光合特性差异; 探究叶片与枝干光合 $\left(P_{g}\right)$ 的主要的影响因子; 量 化枝干光合在其植株个体水平上的贡献。

\section{1 研究区概况与研究方法}

\section{1 研究区概况}

研究区位于古尔班通古特沙漠的南缘,地理坐标为 $87^{\circ} 55^{\prime} \mathrm{E}, 44^{\circ} 22^{\prime} \mathrm{N}$, 海拔 $460 \mathrm{~m}$ 。古尔班通古特沙漠位于 新疆准噶尔盆地中央, 是中国面积最大的固定、半固定 沙漠,面积有大约 4.88 万 $\mathrm{km}^{2}$, 也是中国第二大沙漠。 该区属于典型的温带干旱气候, 夏季炎热, 高温可达 40 ${ }^{\circ} \mathrm{C}$ 以上, 冬季寒冷且漫长, 有 5 个月的平均气温在 $0{ }^{\circ} \mathrm{C}$ 以下。年降水量 70-150 mm, 年蒸发量约 $1000 \mathrm{~mm}$ 。 研究区植被种类比较丰富,主要有白梭梭 (Haloxylon persicum)、梭梭 (Haloxylon ammodendron)、淡枝沙拐東 ( Calligonum leucocladum)、琵琶柴（Reaumuria soongorica)、柽柳 ( Tamarix chinensis) 等。5 月份短命和 类短命植物发育, 平均盖度可达 $40 \%$ 左右, 主要种有尖

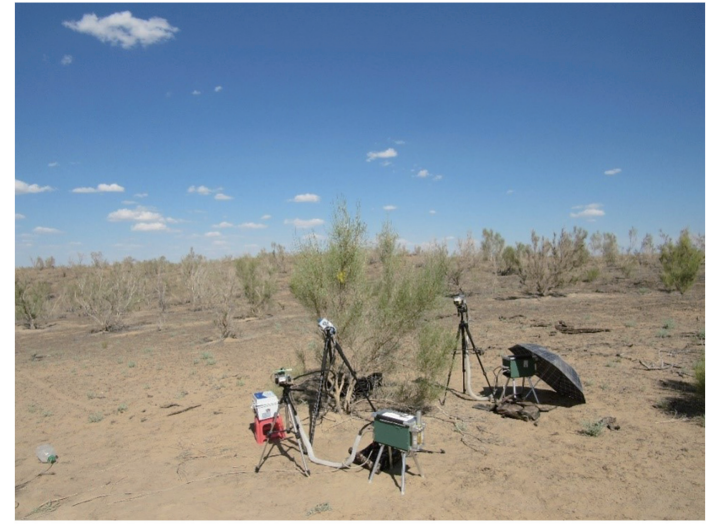

图 1 枝干光合测量装置

Fig.1 Photosynthesis measuring device for branches and stems 嚎陇牛儿苗 (Erodium oxyrrhynchum)、角果藜(Ceratocarpus arenarius)、荒漠庭荠(Alyssum desertorum) 等,在沙丘 底部或丘间低地广泛分布着地衣植物为主的生物结皮, 其中还有微生物、藻类和苔藓植物等多种类型, 其组成 和分布因环境而异, 是除种子植物以外维持该沙漠地表稳定的重要生物因子 ${ }^{[26]}$ 。

研究对象为长势良好的多年生白梭梭,于 2020 年 7 月白梭梭生长旺盛季开展试验。选取 3 棵株高 $(2.3 \pm$ $0.12) \mathrm{m}$ 、冠幅 $(1.8 \pm 0.2) \mathrm{m} \times(1.0 \pm 0.2) \mathrm{m}$ 、基径 $(49 \pm 3) \mathrm{mm}$ 相似的白梭梭, 每棵按枝干直径大小划分 $\mathrm{A}$ 级 $(13.36 \pm 0.84) \mathrm{mm}, \mathrm{B}$ 级 $(8.37 \pm 0.25) \mathrm{mm}, \mathrm{C}$ 级 $(4.94 \pm 0.49) \mathrm{mm}$ 。分别测定各径级枝干光响应曲线及光合日变 化特征, 辅以监测环境因子及相关叶片/枝干功能性状。

1.2 光响应曲线测定及拟合

\subsection{1 叶片光响应曲线}

使用 LI- 6400 便携式光合仪 ( Li-Cor, Lincoln, NE, USA), 选择植株生理活动相对活跃的上午时段 $(8: 00-12: 00)$ 测量, 光源使用 $2 \mathrm{~cm} \times 3 \mathrm{~cm}$ 自带红蓝光源叶室控制, $\mathrm{CO}_{2}$ 浓度采用外带液化 $\mathrm{CO}_{2}$ 小钢瓶由二氧 化碳注人系统控制, 稳定参比 $\mathrm{CO}_{2}$ 浓度在 $400 \mu \mathrm{mol} / \mathrm{mol}$, 设定气体流量 $\mathrm{Flow}=500 \mu \mathrm{mol} / \mathrm{s}$, 设定光强梯度为: $2000 、 1600 、 1200 、 800 、 400 、 200 、 150 、 100 、 50 、 0 \mu \mathrm{mol} \mathrm{m} \mathrm{s}^{-2}$ 。叶片平铺于叶室后首先在 $2000 \mu \mathrm{mol} \mathrm{m} \mathrm{m}^{-2}$ 的光 强下适应 5-8 min 至参数稳定, 启用光响应自动测量程序开始测量, 程序默认最小稳定时间 $120 \mathrm{~s}$, 变异系数 $<0.5$ 记录结果。光响应曲线测定结束后测定叶片面积进行换算。

\subsection{2 枝干光响应曲线}

同时，使用另一台 LI- 6400 便携式光合仪，预热检查后将样品室连接 P-Chamber ( MilletHill Biotech Co.， Ltd, China), P-Chamber 叶室包裹在待测枝干上, 测定面积约 $25 \mathrm{~cm}^{2}$, 固定密封后在旁边吹气检查 LI- 6400 的 参数值, 确保不漏气。参比 $\mathrm{CO}_{2}$ 浓度控制方法及设定参数同上, 光强由 P-Chamber 主机控制, 设置梯度与叶片 相同。光适应稳定后, 改变光强并记录测定结果 ${ }^{[27]}$ 。

1.2.3 叶片/枝干光响应曲线拟合

采用 4 种典型的光响应曲线模型, 直角双曲线模型 $(R H)$ 、非直角双曲线模型 (NRH), 指数方程模型 
(EE) 和修正的直角双曲线模型 (MRH), 分别对白梭梭的叶片和枝干进行光响应曲线拟合, 并与实测值比较 后选出最优模型 ${ }^{[28]}$ 。

\section{3 枝干/叶片光合日变化测定}

选择天气晴朗的一天, 于 $8: 00-18: 00$, 每隔 $2 \mathrm{~h}$ 测定叶片的净光合速率 $\left(P_{n}\right), \mathrm{B}$ 级枝干的净光合速率、呼 吸速率, 光强设为测量时间点外界光强, $\mathrm{CO}_{2}$ 参比浓度稳定在 $400 \mu \mathrm{mol} / \mathrm{mol}$ 。利用土壤温湿度测量仪( TDR150(6445), FieldScout, USA) 在测量时间点测定植株就近的土壤层 0-5 cm、5-10 cm 的土壤温度和土壤含水 量。温湿度记录仪 (MX2301 A, HOBO, USA ) 测量空气湿度和温度变化, 自动气象站实时监测气象因子, 结果 见图 2。
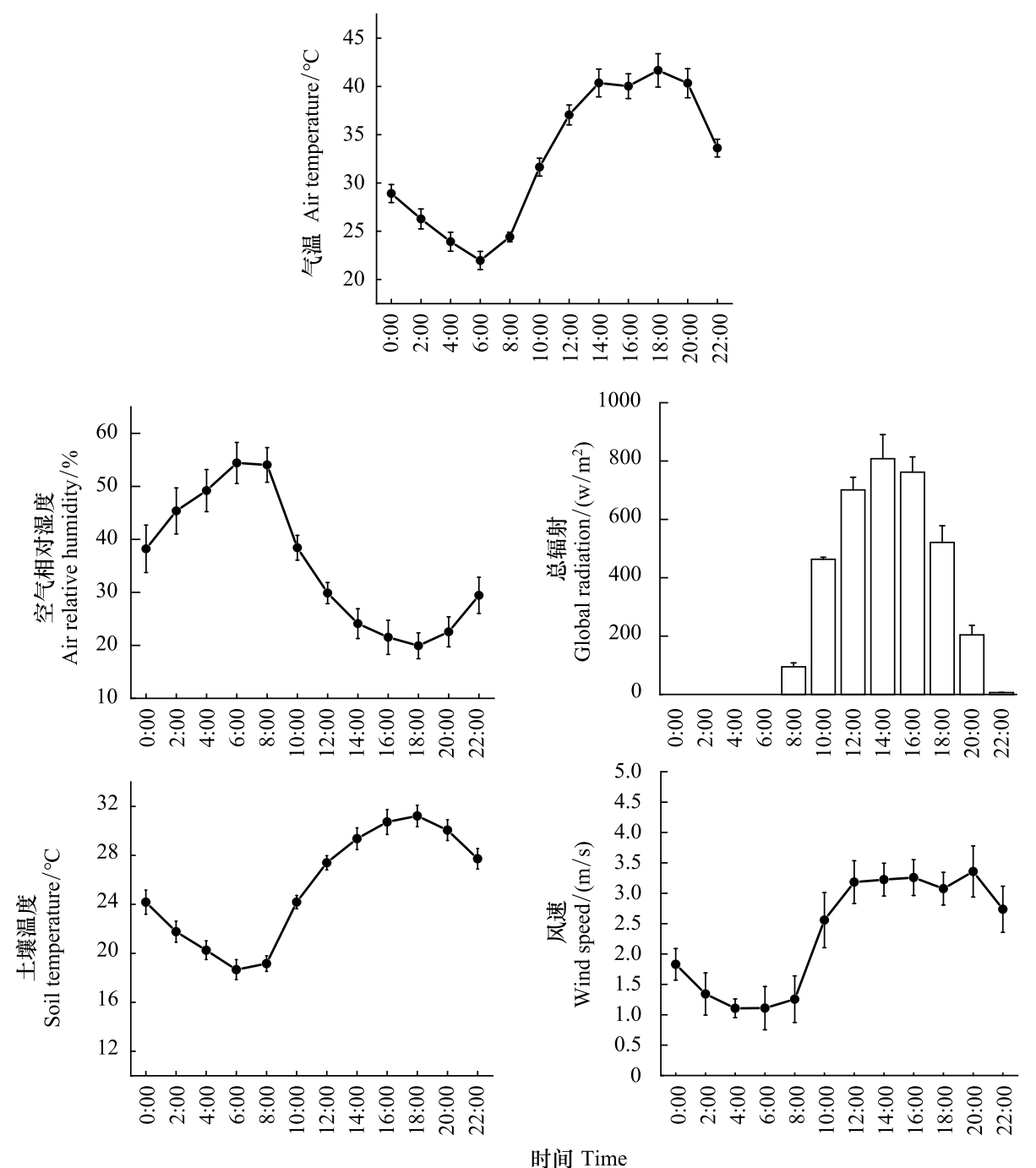

图 2 研究期内环境因子的平均日变化 (10d)

Fig.2 Average daily change of environmental factors during the study period

枝干光合 $\left(P_{g}\right)$ 指光照下枝干 $\mathrm{CO}_{2}$ 释放速率 $\left(R_{l i}\right)$ 与黑暗条件下枝干 $\mathrm{CO}_{2}$ 释放速率 $\left(R_{d}\right)$ 的差值。其表达 式 ${ }^{[7]}$ 如下:

$$
P_{g}=\left|R_{d}-R_{l i}\right|
$$

枝干光合再固定比例是指枝干光合 $\left(P_{g}\right)$ 占枝干暗呼吸速率 $\left(R_{d}\right)$ 的百分比, 其表达式 ${ }^{[18]}$ 如下:

$$
\% \text { refixation }==\left|R_{d}-R_{l i}\right| / R_{d}
$$


本实验中, 用枝干光合固定 $\mathrm{CO}_{2}$ 的总量 $\left(P_{g} \times S_{s}, P_{g}\right.$ : 枝干光合, $S_{s}$ : 枝干总面积 $)$ 占植株光合总量 $\left(P_{s} \times S_{s}+\right.$ $P_{n} \times S_{l}, P_{n}$ : 叶片净光合速率, $S_{l}$ : 叶片总面积) 的比值来表征枝干光合在植株个体水平上的贡献。

\section{4 生理指标测定}

黎明前剪取白梭梭叶片和不同径级枝干迅速放人冰盒运回实验室分析。

\subsection{1 叶绿素含量}

分别取叶片 $0.1 \mathrm{~g}$ 、枝干 $1 \mathrm{~g}$, 剪碎,用 $95 \%$ 乙醇与 $80 \%$ 丙酮 (1:1) 混合液 $25 \mathrm{~mL}$ 暗处浸提 $24 \mathrm{~h}$,提取液在波 长 $663 、 645 \mathrm{~nm}$ 下测定吸光度,并应用公式计算叶绿素 $\mathrm{a} 、 \mathrm{~b}$ 含量 $(\mathrm{mg} / \mathrm{g})^{[29]}$ 。

$$
\begin{aligned}
& C_{\mathrm{a}}=12.7 A_{663}-2.69 A_{645} \\
& C_{\mathrm{b}}=22.9 A_{645}-4.68 A_{663} \\
& C_{T}=C_{\mathrm{a}}+\mathrm{C}_{\mathrm{b}} \\
& \text { 叶绿体色素含量 }=\frac{C \times V_{T}}{F W \times 1000} \times n
\end{aligned}
$$

式中, $C_{\mathrm{a}}$ : 叶绿素 $\mathrm{a}$ 的浓度; $C_{\mathrm{b}}$ : 叶绿素 $\mathrm{b}$ 的浓度; $C_{T}$ : 叶绿素的总浓度; $A_{645} 、 A_{663}$ : 叶绿素溶液在波长 $645 \mathrm{~nm}$ 和 $663 \mathrm{~nm}$ 处的吸光度; $C$ : 叶绿体色素的浓度 $(\mathrm{mg} / \mathrm{L}) ; \mathrm{FW}$ : 鲜重 $(\mathrm{g}) ; V_{T}$ : 提取液总体积 $(\mathrm{mL}) ; n$ : 稀释倍数。

\subsection{2 含水量及地上生物量等的测定}

分别取白梭梭叶片和各级枝干 $1 \mathrm{~g} 、 4 \mathrm{~g}$ 放人盛有蒸馏水的雉形瓶内, 于低温冰箱保存 $24 \mathrm{~h}$ 后 $65{ }^{\circ} \mathrm{C}$ 烘干 至恒重。白梭梭平地采伐后装袋运回实验室, 后将枝条截成约 $20 \mathrm{~cm}$ 长的小枝并按直径分成 $\mathrm{A} 、 \mathrm{~B}$ 和 $\mathrm{C}$ 三组, 对应直径分别为: $\mathrm{dA}>10 \mathrm{~mm}, 5 \mathrm{~mm} \leqslant \mathrm{~dB} \leqslant 10 \mathrm{~mm}, \mathrm{dC}<5 \mathrm{~mm}$ 。采用直径长度估算法计算枝干的表面积。选 取样地生长状况相似的 10 棵白梭梭, 取若干叶片用于计算比叶面积, 用比叶面积来估算叶片面积和直径小于 $1 \mathrm{~mm}$ 的枝条面积, 测量完毕后于 $65{ }^{\circ} \mathrm{C}$ 烘干至恒重。总碳测定使用 multi N/C 2100 碳氮分析仪 (multi N/C 2100 TOC, analytikjena, Germany)。

\section{5 数据分析}

采用配对样本 $t$ 检验 (Paired-samples $t$-test) 的方法分析白梭梭叶片和各级枝干叶绿素含量差异、叶绿素 $\mathrm{a} / \mathrm{b}$, 应用 Spearman 相关性检验分析影响白梭梭叶片光合, 枝干光合和枝干呼吸的环境影响因子。数据由 Excel 2019 和 SPSS 20 进行处理, 图表采用 Origin 9.0 绘制, 图表中的数据均为平均值 \pm 标准误差 $($ Mean \pm SE)。

\section{2 结果}

\section{1 枝干/叶片叶绿素含量比较}

实验测定结果表明白梭梭叶片叶绿素含量与枝干叶绿素含量差异显著 $(P<0.01)$, 叶片叶绿素 $\mathrm{a}$ 和叶绿 素 b 含量均明显高于对应枝干的叶绿素含量, 叶片总叶绿素含量是枝干总叶绿素含量 9-16 倍, 而在各径级 枝干之间叶绿素含量未检验出显著性差异。叶绿素 $\mathrm{a} / \mathrm{b}$ 的值在白梭梭叶片和枝干间差异显著 $(P<0.05)$, 枝 干叶绿素 $\mathrm{a} / \mathrm{b}$ 的值相当于对应叶片的 $63 \%-72 \%$ 。 B 级枝和 $\mathrm{C}$ 级枝叶绿素 $\mathrm{a} / \mathrm{b}$ 相似, A 级枝略低于 B、 $\mathrm{C}$ 级 枝,但未检出显著性差异,表明各径级枝干之间叶绿素 a/b 差异不明显(图 3)。

2.2 枝干/叶片光响应曲线拟合及光合特征比较

\subsection{1 光响应曲线拟合}

由表 1 可知,对白梭梭叶片的光响应曲线拟合中, RH 和 NRH 对 $P_{n, m}$ 的拟合结果存在高估现象, $\mathrm{EE}$ 对 LCP 的拟合结果低于实测值, MRH 的拟合结果较精确,适合作为最优模型。对白梭梭枝干的光响应曲线拟合 中, RH 和 NRH 和 NRH 高估了 $P_{n, m}$, 不符合实际测量结果 (未测得枝干净光合为正值), 而 $\mathrm{EE}$ 仅能够对 $P_{n, m}$ 有较精确的拟合, MRH 模型各项拟合指标较精确,综上所述,在对白梭梭叶片/枝干的光响应曲线进行拟合 时, 应优先考虑 $\mathrm{MRH}$, 以提高拟合结果的精确度, 此外, 不能单纯将 $R^{2}$ 作为模型拟合优劣的判断标准。 


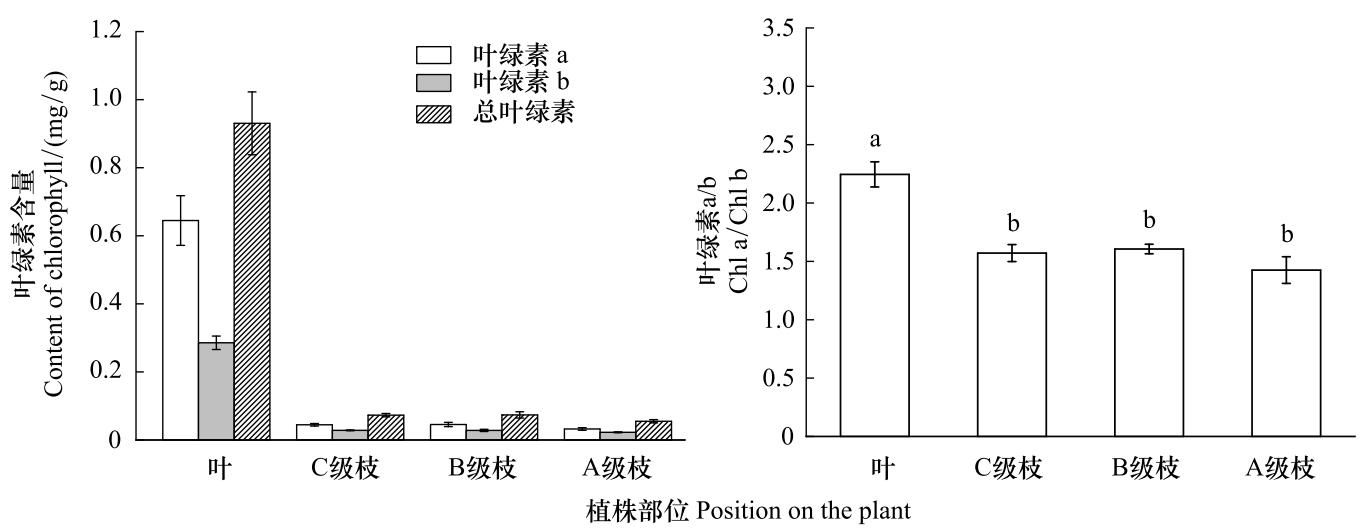

图 3 白梭梭叶片与各径级枝叶绿素含量及叶绿素 $\mathbf{a} / \mathbf{b}$ 的平均值

Fig.3 The average value of content of chlorophyll and chlorophyll $\mathbf{a} / \mathrm{b}$ in leaves and stems of $\mathrm{H}$. persicum. Different letters on the bar chart indicate significant differences in position on the plant

柱状图上的不同字母表示植株部位之间差异显著 $(P<0.05)$; A 级枝:直径 $>10 \mathrm{~mm}$; B 级枝: $5 \mathrm{~mm} \leqslant$ 直径 $\leqslant 10 \mathrm{~mm}$; 级枝: 直径 $<5 \mathrm{~mm}$

\subsection{2 光合特征比较}

由图 4 可知, 白梭梭叶片与各径级枝干的光响应曲线存在较大差异 $(P<0.01)$ 。叶片光合总量是 $P_{g}$ 总量 的 9.8-17.3 倍, 未能测得枝干净光合为正值, A 级枝 $P_{g}$ 最大, B 级枝和 C 级枝分别占 A 级枝的 $61 \% 、 56 \%$ 。

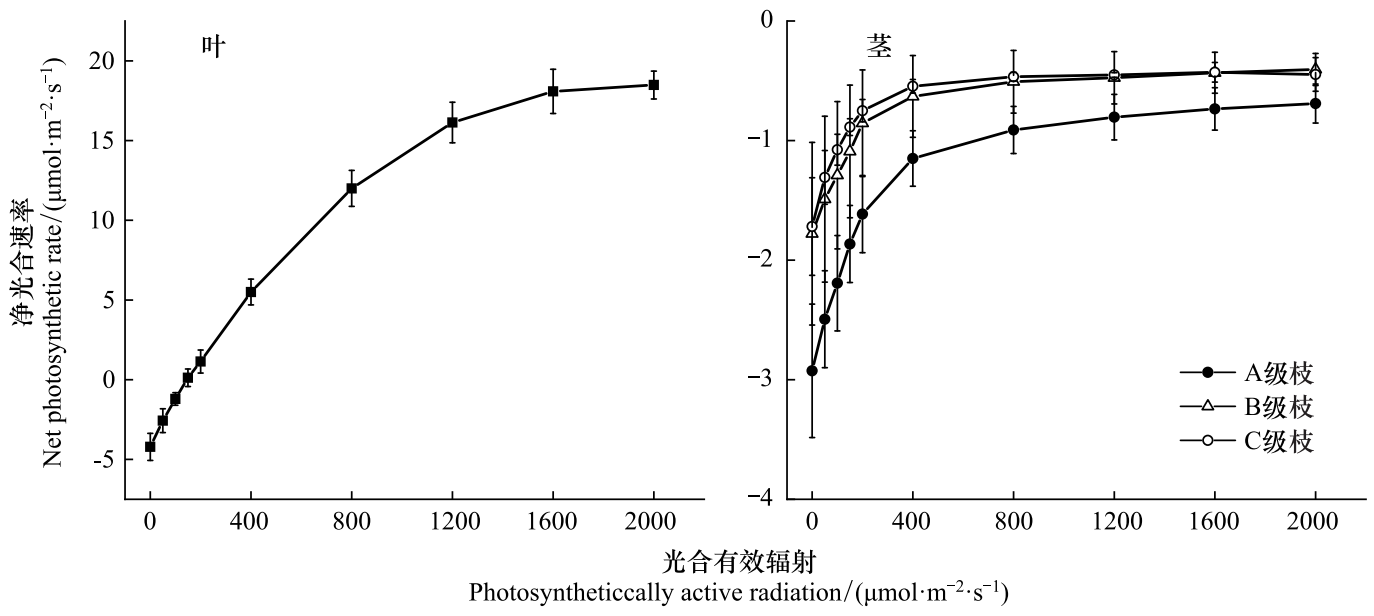

图 4 白梭梭叶和各径级枝的光响应曲线

Fig.4 Light response curves in leaf and stems of $H$. persicum

由表 1 可知,白梭梭枝干光饱和点低于叶片, $\mathrm{A}$ 级枝干至 $\mathrm{C}$ 级枝干光饱和点逐渐减小 $(\mathrm{A}$ 级枝 $>\mathrm{B}$ 级枝 $>\mathrm{C}$ 级枝)。光响应曲线拟合参数结果显示, 白梭梭叶片表观量子效率 (AQE) 约 0.029 ,枝干 AQE 较叶片低,在 0.006- 0.014 。叶片暗呼吸速率大于各径级枝干的暗呼吸速率, $\mathrm{A}$ 级枝干到 $\mathrm{C}$ 级枝干暗呼吸速率逐渐减小 ( $\mathrm{A}$ 级枝 $>\mathrm{B}$ 级枝 $>\mathrm{C}$ 级枝)。

2.3 枝干/叶片光合特征日变化

在 $8: 00-10: 00$ 空气温度快速上升, 空气湿度与之相反, $8: 00-18: 00$ 温度总体保持升高 (图 2)。叶片光 合速率在 8:00-10:00 上升幅度最大,达 $186 \%$; 对应枝干上升幅度较低, 仅 $17 \%$, 说明白梭梭叶片较枝干对外 界环境因子的响应更迅捷。12 点时白梭梭叶片光合速率下降,降幅为 $23 \%$,但对应枝干光合上升了 $29 \%$, 仅 变化了 $0.25 \mu \mathrm{mol} \mathrm{m} \mathrm{m}^{-2} \mathrm{~s}^{-1}$ 。白梭梭枝干呼吸速率在 8:00-14:00 持续增多, 之后保持平稳, 枝干光合变化与之 
相同 (图 5)。测定时间范围内白梭梭叶片光合变化幅度明显高于枝干,并且叶片和枝干变化不同步。

表 1 白梭梭叶片和各径级枝干的光响应曲线拟合

Table 1 Fitting of light response curves of leaves and stems in $H$. persicum

\begin{tabular}{|c|c|c|c|c|c|c|c|}
\hline \multirow{2}{*}{$\begin{array}{l}\text { 部位 } \\
\text { Position }\end{array}$} & \multirow{2}{*}{$\begin{array}{l}\text { 模型 } \\
\text { Model }\end{array}$} & \multicolumn{6}{|c|}{ 拟合参数和 $R^{2}$ Fitted parameters and $R^{2}$} \\
\hline & & LSP & LCP & $R_{d}$ & $P_{n, m}$ & $\mathrm{AQE}$ & $R^{2}$ \\
\hline \multirow{7}{*}{ 叶片 Leaf } & MEA & & & 4.21 & 18.49 & & \\
\hline & RH & & 139 & 4.54 & 35.34 & 0.037 & 0.9945 \\
\hline & NRH & & 155 & 3.89 & 25.5 & 0.026 & 0.9988 \\
\hline & $\mathrm{EE}$ & & 45 & 1.21 & 20.94 & 0.027 & 0.9980 \\
\hline & MRH & 1908 & 150 & 4.04 & 18.53 & 0.029 & 0.9998 \\
\hline & MEA & & & 1.72 & -0.45 & & \\
\hline & $\mathrm{RH}$ & & & 1.74 & 1.41 & 0.014 & 0.9881 \\
\hline C 级枝 & NRH & & & 1.71 & 1.31 & 0.008 & 0.9976 \\
\hline \multirow[t]{4}{*}{ Stem C } & $\mathrm{EE}$ & & & & -0.45 & & 0.9984 \\
\hline & MRH & 1204 & & 1.73 & -0.42 & 0.012 & 0.9956 \\
\hline & MEA & & & 1.78 & -0.41 & & \\
\hline & RH & & & 1.82 & 1.55 & 0.010 & 0.9815 \\
\hline $\mathrm{B}$ 级枝 & NRH & & & 1.78 & 1.38 & 0.006 & 0.9950 \\
\hline \multirow[t]{4}{*}{ Stem B } & $\mathrm{EE}$ & & & & -0.45 & & 0.9919 \\
\hline & MRH & 1509 & & 1.81 & -0.42 & 0.009 & 0.9839 \\
\hline & MEA & & & 2.93 & -0.69 & & \\
\hline & $\mathrm{RH}$ & & & 2.98 & 2.53 & 0.013 & 0.9922 \\
\hline $\mathrm{A}$ 级枝 & NRH & & & 2.93 & 2.31 & 0.009 & 0.9985 \\
\hline \multirow[t]{2}{*}{ Stem A } & $\mathrm{EE}$ & & & & -0.76 & & 0.9953 \\
\hline & MRH & 1812 & & 2.96 & -0.72 & 0.012 & 0.9938 \\
\hline
\end{tabular}

$\mathrm{LSP}$ 为光饱和点; LCP 为光补偿点; $R_{d}$ 为暗呼吸速率; $P_{n, m}$ 为最大净光合速率; $\mathrm{AQE}$ 为表观量子效率; $\mathrm{MEA}:$ 实测值; RH: 直角双曲线; $\mathrm{NRH}$ : 非直角双曲线; $\mathrm{EE}$ : 指数方程; $\mathrm{MRH}$ : 修正直角双曲线

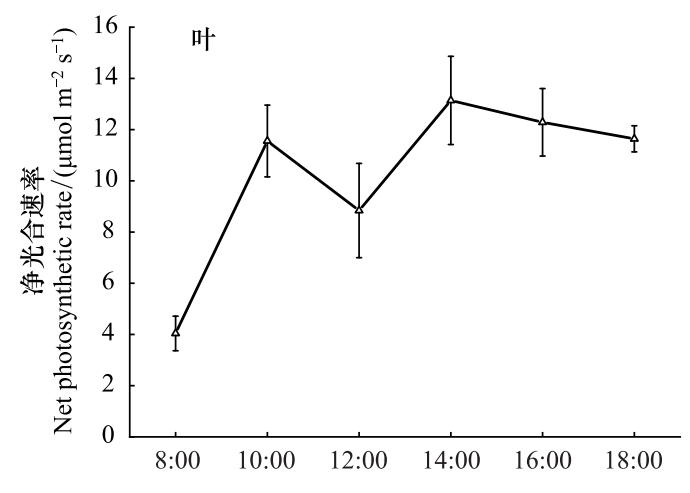

图 5 白梭梭叶和枝净光合速率日变化特征

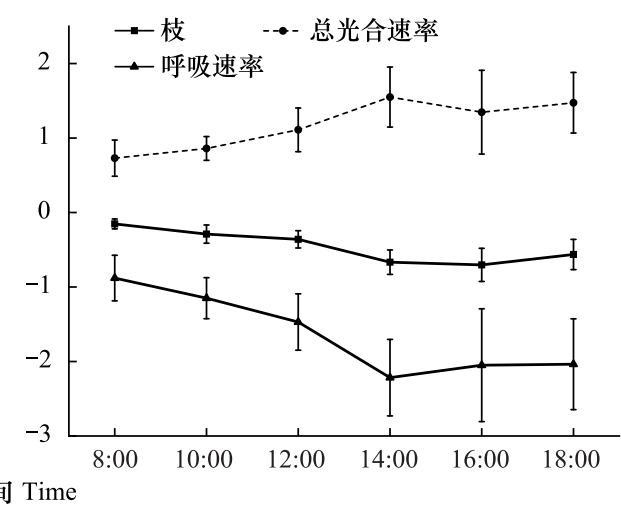

时间 Time

Fig.5 Daily change in net photosynthetic rate of leaf and stem of $H$. persicum

\section{4 枝干/叶片光合特征影响因素}

实验结果表明 (表 2), 白梭梭叶片的相对含水量明显高于各级枝干, 而 $\mathrm{A}$ 级枝干相对含水量低于 $\mathrm{C}$ 级枝

干。C 级枝干较 A、B 级枝干呼吸速率强, 其枝干光合也较高 (图 4)。比叶面积远高于比枝面积, 是其 9-26 倍。叶片总碳含量约占枝干总碳含量的 $89 \%$, 但各径级枝干间差异不显著。叶片干物质含量和总碳含量都 明显低于枝干,而各径级枝干间差异不显著。 
表 2 白梭梭不同部位的各项参数

Table 2 Various parameters of different parts of $H$. persicum

\begin{tabular}{lcccc}
\hline $\begin{array}{l}\text { 植株部位 } \\
\text { Position of plant }\end{array}$ & $\begin{array}{c}\text { 相对含水量 } / \% \\
\text { RWC }\end{array}$ & $\begin{array}{c}\text { 比叶面积 } /\left(\mathrm{cm}^{2} / \mathrm{g}\right) \\
\text { SLA }\end{array}$ & $\begin{array}{c}\text { 干物质含量 } \\
\text { LDMC }\end{array}$ & $\begin{array}{c}\text { 总碳 } /(\mathrm{mg} / \mathrm{g}) \\
\text { TC }\end{array}$ \\
\hline 叶片 Leaf & $92.56 \pm 1.30^{\mathrm{A}}$ & $88.28 \pm 22.41^{\mathrm{A}}$ & $0.325 \pm 0.009^{\mathrm{A}}$ & $430.4 \pm 6.0^{\mathrm{A}}$ \\
C 级枝 Stem C & $74.42 \pm 2.26^{\mathrm{Bb}}$ & $9.12 \pm 0.85^{\mathrm{Bb}}$ & $0.655 \pm 0.012^{\mathrm{Bb}}$ & $482.0 \pm 9.1^{\mathrm{Bb}}$ \\
B 级枝 Stem B & $80.78 \pm 1.72^{\mathrm{Bc}}$ & $5.14 \pm 0.17^{\mathrm{Bc}}$ & $0.684 \pm 0.019^{\mathrm{Bb}}$ & $482.3 \pm 6.5^{\mathrm{Bb}}$ \\
A 级枝 Stem A & $86.48 \pm 0.90^{\mathrm{Ba}}$ & $3.36 \pm 0.24^{\mathrm{Ba}}$ & $0.695 \pm 0.016^{\mathrm{Bb}}$ & $482.0 \pm 4.5^{\mathrm{Bb}}$ \\
\hline
\end{tabular}

根据最小显著差异法,表中同一列不同大写字母表示在 0.05 水平上植株枝与叶片之间差异显著,同一列不同小写字母表示在 0.05 水平上 枝间差异显著; RWC: 相对含水量 Relative water content; SLA : 比叶面积 Specific leaf area; LDMC: 干物质含量 Dry matter content; TC: 总碳 Total carbon

从表 3 可知, 叶片光合速率与空气温度、空气相对湿度、光合有效辐射有较强的相关性,此外,土壤含水量 和土壤温度与叶片光合速率相关性叶较强。深层土壤含水量 $(10 \mathrm{~cm})$ 较浅层土壤含水量 $(5 \mathrm{~cm})$ 与叶片光合 速率的相关性更强, 表明叶片光合速率受深层土壤含水量 $(10 \mathrm{~cm})$ 的影响更大。枝干呼吸速率与光合有效辐 射、空气温度和空气相对湿度相关性较强,但枝干光合与环境因子未检出显著相关性,表明枝干光合的变化基 本不受环境因子的影响。图 6 为白梭梭叶片光合速率与枝干光合的线性相关分析,根据 $R^{2}$ 可知,枝干光合与 叶片光合及枝干呼吸速率有显著的线性相关关系, 表明叶片和枝干光合存在一定联系。

表 3 白梭梭不同部位的光合与环境因子的相关系数

Table 3 Correlation coefficients between environmental factors and photosynthesis in different parts of $\boldsymbol{H}$. persicum

\begin{tabular}{cllllllllll}
\hline & $R d_{s}$ & \multicolumn{1}{c}{$P_{g}$} & \multicolumn{1}{c}{$\mathrm{PAR}$} & $T_{a}$ & \multicolumn{1}{c}{$R H$} & $\mathrm{SWC}_{5}$ & $T_{s 5}$ & $\mathrm{SWC}_{10}$ & $T s_{10}$ & $P_{n}$ \\
\hline$R d_{s}$ & 1 & $0.947^{* *}$ & $0.533^{*}$ & $0.527^{*}$ & $-0.527^{*}$ & 0.334 & 0.273 & 0.082 & 0.210 & $0.612^{* *}$ \\
$P_{g}$ & $0.947^{* *}$ & 1 & 0.386 & 0.423 & -0.423 & 0.220 & 0.259 & 0.069 & 0.174 & $0.501^{*}$ \\
$P_{n}$ & $0.612^{* *}$ & $0.501^{*}$ & $0.624^{* *}$ & $0.643^{* *}$ & $-0.643^{* *}$ & $0.508^{*}$ & $0.509^{*}$ & $0.557^{*}$ & $0.544^{*}$ & 1 \\
\hline
\end{tabular}

$*$ 为 0.05 水平上显著; $* *$ 为 0.01 水平上显著; $P_{n}$ : 叶净光合速率 Net photosynthetic rate $\left(\mu \mathrm{mol} \mathrm{m} \mathrm{m}^{-2} \mathrm{~s}^{-1}\right) ; R_{d}$ : 暗呼吸速率 Dark respiration $\operatorname{rate}\left(\mu \mathrm{mol} \mathrm{m}{ }^{-2} \mathrm{~s}^{-1}\right) ; P_{g}$ : 枝干总光合速率 Gross photosynthesis rate in stem $\left(\mu \mathrm{mol} \mathrm{m} \mathrm{m}^{-2} \mathrm{~s}^{-1}\right)$; PAR: 光合有效辐射 Photosynthetically available radiation; $T_{a}$ : 空气温度 Air temperature $\left({ }^{\circ} \mathrm{C}\right) ; R H$ : 相对湿度 Relative humidity $(\%)$; SWC $5: 5 \mathrm{~cm}$ 土壤含水量 Soil water content under $5 \mathrm{~cm} ; T s_{5}$ : $5 \mathrm{~cm}$ 土壤温度 Soil temperature under $5 \mathrm{~cm}\left({ }^{\circ} \mathrm{C}\right)$; $\mathrm{SWC}_{10}: 10 \mathrm{~cm}$ 土壤含水量 Soil water contentunder $10 \mathrm{~cm} ; T s_{10}: 10 \mathrm{~cm}$ 土壤温度 Soil temperature under $10 \mathrm{~cm}\left({ }^{\circ} \mathrm{C}\right)$
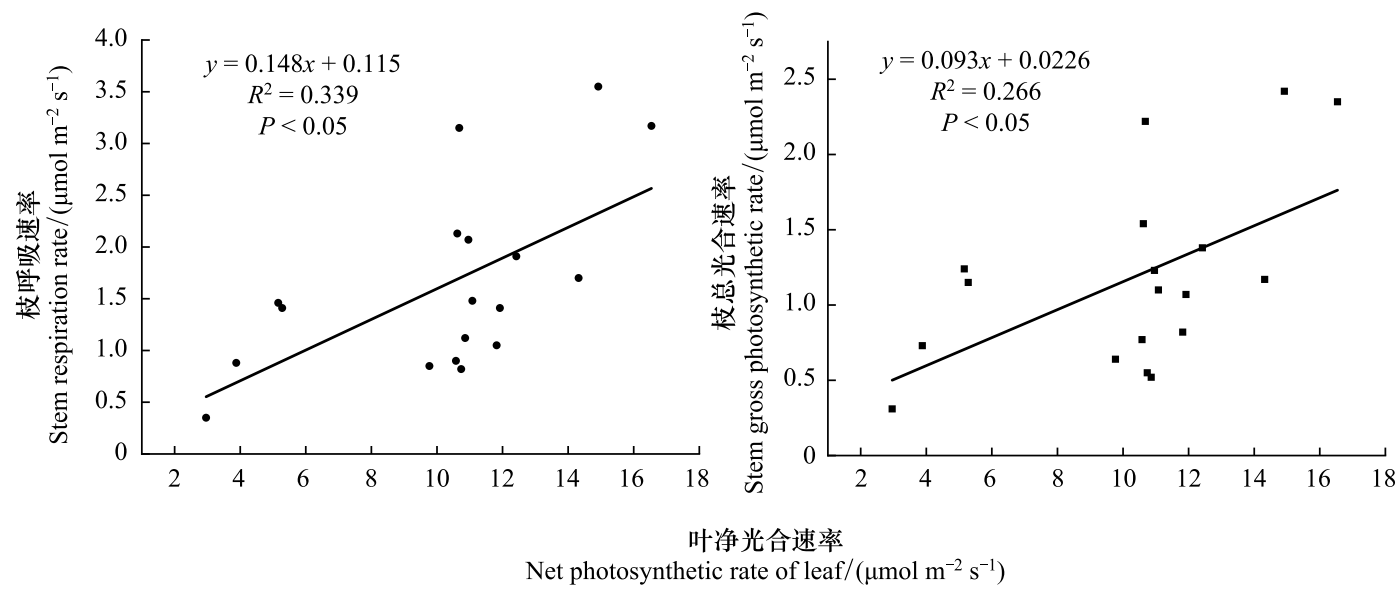

图 6 白梭梭叶片光合与枝干光合的线性关系

Fig.6 The linear relationship of photosynthetic rate between leaves and branches of $\mathrm{H}$. persicum 
2.5 枝干光合对自身呼吸 $\mathrm{CO}_{2}$ 的再固定及其在植株个体水平上的贡献

白梭梭枝干光合平均 $\mathrm{CO}_{2}$ 固定率约 $73 \%$, 能够维持在较高水平, 最高可达 $90 \%$ (图 7), 显著减少了枝干呼 吸释放的 $\mathrm{CO}_{2}$ 。 $\mathrm{CO}_{2}$ 再固定比率在 16 点前逐步下降。

在植株个体水平上,白梭梭枝干总面积是叶片总面积的 1.2-2.1 倍, 枝干光合固定二氧化碳的量对植株 个体水平上固碳量的贡献为 $10.1 \%-21.2 \%$, 平均贡献比约 $15.4 \%$, 而且该比值在上午先下降后上升, 10 点该 比值最低, 归因于叶片光合速率的快速提升, 在炎热干燥的中午和下午,植物处于干旱胁迫时该比值并没有明 显变化(图 8)。

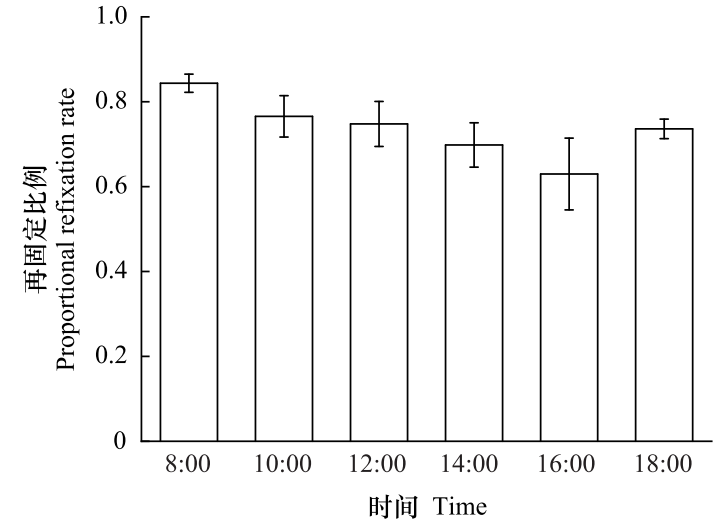

图 7 枝呼吸再固定比例的日变化

Fig.7 Daily change in proportional refixation rate of respiration in stem

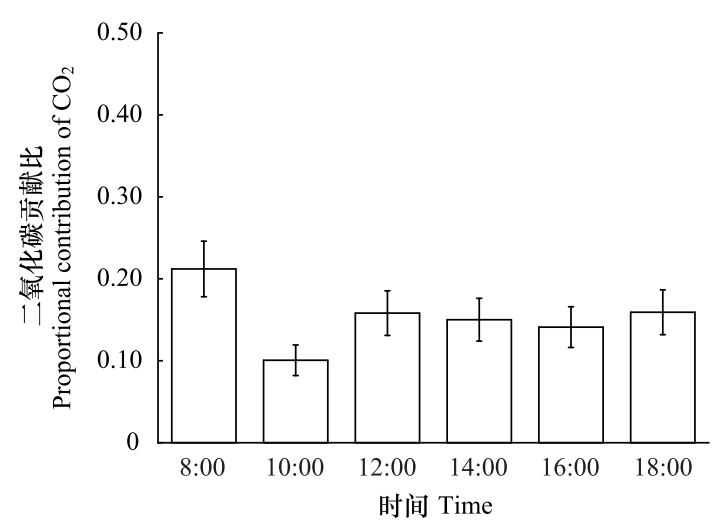

图 8 枝干光合吸收二氧化碳贡献比的日变化

Fig.8 Daily change in proportional contribution of $\mathrm{CO}_{2}$ assimilation in stem photosynthesis

\section{3 讨论}

\section{1 白梭梭枝干和叶片的叶绿素含量差异}

本实验中, 白梭梭叶片和枝干叶绿素含量差异显著。白梭梭在进化过程中为减少蒸腾作用, 叶片逐渐退 化为同化枝,但依旧保持叶片光合最优化分配, 叶绿素含量远高于枝干。王莹 ${ }^{[30]}$ 对柏树、红柳、小叶丁香和家 槐等 44 种植物的叶片和枝干叶绿素含量进行测定, 结果表明叶片叶绿素含量平均是枝干的 19.76 倍, 与王文 杰等 ${ }^{[21]}$ 对林木非同化器官光合功能统计结果相似。枝干具有较低的叶绿素 $\mathrm{a} / \mathrm{b}$ 比例, 叶绿素 $\mathrm{b}$ 丰度高有利 于对光能的捕捉和传递, 这是典型阴生植物的特点 ${ }^{[22]}$ 。Levizou 等 ${ }^{[31]}$ 对 24 种植物的研究还表明,枝干叶绿素 比率在阳面和阴面无显著性差异, 认为可能与枝干内部特定的微环境有关。此外, 因为叶片的遮挡, 枝干处光 照总量低于叶片, 这可能也是叶绿素差异的原因之一。Wittmann 等 ${ }^{[32]}$ 对杨树遮光处理后发现枝干叶绿素含 量上升了约 40\%, 表明光照影响叶绿素含量。叶绿素差异形成可能是植物对光照环境的适应。

\section{2 白梭梭枝干和叶片的光合特征差异}

本实验中, 白梭梭枝干光饱和点低于叶片, 这与 Wittmann 等 ${ }^{[32]}$ 对白杨和山毛榉的研究结果一致。白梭 梭各径级枝干的 $\mathrm{CO}_{2}$ 释放量与 Cernusak 等 ${ }^{[18]}$ 对白松 (Pinus monticola Dougl. ex D. Don) 的测定结果相似,枝干 光合 $P_{g}$ 范围在 $0-2.7 \mu \mathrm{mol} \mathrm{m} \mathrm{m}^{-2} \mathrm{~s}^{-1}$, 远低于叶片的光合总量。木本植物枝干结构和叶片结构通常存在较大差 异, 这些差异是影响光合功能特性的原因。木本植物茎部软木 (栓皮) 对光有高吸收性和低透射性, 导致枝干 处光合有效辐射的利用率较低,这是枝干光合的主要限制因素 ${ }^{[32]}$ 。通常认为, 枝干释放出的大部分 $\mathrm{CO}_{2}$ 是由 树皮下的形成层和边材中的活细胞产生的,枝干光合同化了其中一部分 $\mathrm{CO}_{2}$, 此外, 枝干中的微生物和大型生 物的呼吸,木质部和韧皮部中溶解的 $\mathrm{CO}_{2}$, 也可能是枝干释放的 $\mathrm{CO}_{2}$ 中的一部分 ${ }^{[33]}$ 。

本实验中枝干暗呼吸速率、枝干光合、枝干光合与枝干呼吸速率的比率, 从 A 级至 $\mathrm{C}$ 级逐步减小 (图 4), 
这与 Hölttä 等 ${ }^{[34]}$ 建立的模型恰好相反, 该模型以樟子松 (Pinus sylvestris L.) 为研究对象, 考虑到木质部汁液将 呼吸生成的 $\mathrm{CO}_{2}$ 往上运输并积累。Salomón 等 ${ }^{[35]}$ 对桉树 (Eucalyptus tereticornis) 的研究也表明, $\mathrm{CO}_{2}$ 再固定率 在枝干高度上存在显著差异, 上层枝干再固定率要高于下层。桉树属于高大乔木, 上层阳光较下层充足, 且下 层树皮的粗䊅度大于上层, 而白梭梭则与之不同, 白梭梭属于小乔木, $\mathrm{A}$ 级枝阳光比较充足, 木质化时间较长 但死皮已脱落,枝干表面较 $\mathrm{C}$ 级枝干光滑, 而从枝干相对含水量来看, $\mathrm{A}$ 级枝高于 $\mathrm{C}$ 级枝,其代谢活动相对旺 盛 ${ }^{[36]}$, 此外, 也可能是溶解在木质部下层汁液中的 $\mathrm{CO}_{2}$ 组分较多 ${ }^{[37]}$, 这些差异的综合作用导致白梭梭 $\mathrm{A}$ 级枝 干光合作用更强。

3.3 环境因子对叶片和枝干光合特征的影响

白梭梭叶片光合速率受到空气温度、空气湿度, 土壤含水量和温度等多种环境因子的影响, 枝干呼吸速率 仅与光合有效辐射、空气温度和空气相对湿度存在一定联系, 而枝干光合基本不受环境因子的影响 (表 2), 也 有可能是未达到其响应國值 ${ }^{[18]}$ 。白梭梭枝干对环境因子的敏感性明显低于叶片, 这与 Hölttä 等 ${ }^{[34]}$ 对枝干 $\mathrm{CO}_{2}$ 释放量建立的模型相符, 该模型还预测了枝干呼吸的温度依赖性将大于枝干 $\mathrm{CO}_{2}$ 释放量的温度依赖性。 Nilsen ${ }^{[38]}$ 对鹰爪豆 (Spartium junceum L.) 的研究结果同样表明枝干光合对空气温度、光照强度等环境参数和 水分胁迫的敏感性均低于叶片光合速率。由此可见,枝干光合可能是白梭梭对水分胁迫有较强耐受性的原因 之一。

3.4 枝干光合维持植株碳平衡的重要意义

本实验结果证明,枝干光合能够有效减少植物枝干呼吸释放的 $\mathrm{CO}_{2}$, 在植物处于干旱胁迫的中午和下午, 枝干光合对植株碳平衡的贡献比例仍然维持在稳定水平, 有效降低了植物因为干旱胁迫而导致的碳饥饿风 险。此外, 干旱胁迫造成篎管碳运输功能紊乱, 影响碳在植物体的转运 ${ }^{[39]}$, 枝干光合再固定呼吸释放的 $\mathrm{CO}_{2}$, 降低碳运输能耗并延迟碳耗尽的时间, 从而提升植物抗旱性。众多研究已证明枝干光合能在干旱胁迫中发挥 重要作用 ${ }^{[3,8,10]}$, 因此,枝干光合对维持植株正常生长有不可忽视的作用。

3.5 关于枝干光合的研究建议

本实验探究了枝干光合的变化, 但未测量枝干液流变化情况, 因此不能判断枝干 $\mathrm{CO}_{2}$ 释放量变化与液流 变化的关系。国际上对枝干光合作用的内部机理目前尚不明确, 枝干液流中可能含有较高浓度的 $\mathrm{CO}_{2}$, 这些 $\mathrm{CO}_{2}$ 可能沿径向向外扩散到大气, 从而干扰枝干光合的测定 ${ }^{[33]}$ 。然而, Wittmann 等 $^{[40]}$ 实验结果表明线粒体呼 吸在光照和黑暗条件下是相似的,进而排除线粒体呼吸对枝干 $\mathrm{CO}_{2}$ 释放量的影响; 抑制光呼吸, 改变枝干液流 ( sap flow) 均未明显改变枝干 $\mathrm{CO}_{2}$ 释放量, 证实了光下枝干 $\mathrm{CO}_{2}$ 释放量的减少只能是由于枝干光合作用所致。 而 Salomón 等 ${ }^{[41]}$ 同位素实验表明木质部转运的 $\mathrm{CO}_{2}$ 占到枝干释放的 $\mathrm{CO}_{2}$ 的 $13 \%-38 \%$, 表明木质部转运的 $\mathrm{CO}_{2}$ 在评估枝干光合/呼吸中有显著影响。因而, 建议借助稳定同位素示踪法、树干液流技术等手段, 对植物 根部夜流, 茎部液流和冠层液流的 $\mathrm{CO}_{2}$ 来源和去向展开进一步研究, 在微观上还可以对枝干光合产物的形态 组成及去向进一步研究。此外, 枝干光合能够提升植物抗逆性 (如耐旱性), 对其光合潜能的开发可能成为促 进植物生长和提升作物产量的一种有效手段 ${ }^{[42-43]}$ 。

\section{4 结论}

白梭梭叶片叶绿素含量是枝干叶绿素含量的 12-16 倍, 枝干光饱和点低于叶片, 枝干光合可以有效减少 枝干呼吸释放的 $\mathrm{CO}_{2}$, 维持枝干甚至整棵植株的碳平衡。枝干暗呼吸速率主要受光合有效辐射, 空气温度和 空气相对湿度的影响, 而在一定范围内, 枝干光合 $\left(P_{g}\right)$ 基本不受外界环境因子的影响,对环境因子的依赖程 度远低于叶片光合速率, 这可能是白梭梭抗逆能力较强的原因之一。白梭梭 $\mathrm{A}$ 级枝干的光合作用较 $\mathrm{C}$ 级枝 强, 这可能是枝干表面光滑程度、木质部液流情况等的作用结果。于植株本身而言,植物枝干光合作用可以贡 献植株个体水平固碳量的 $15.3 \%$ 。因此, 本研究成果证明, 忽视枝干光合的贡献来预测未来气候变化背景下 荒漠生态系统碳过程, 可能存在根本性缺陷, 并为进一步完善白梭梭耐旱机制的研究提供理论支撑。 


\section{参考文献 (References) :}

[ 1 ] Nilsen E T. Stem photosynthesis: extent, patterns, and role in plant carbon economy//Gartner B L, ed. Plant Stems: Physiology and Functional Morphology. San Diego: Academic Press, 1995: 223-240.

[ 2 ] Saveyn A N, Steppe K, Ubierna N, Dawson T E. Woody tissue photosynthesis and its contribution to trunk growth and bud development in young plants. Plant, Cell \& Environment, 2010, 33(11) : 1949-1958.

[ 3 ] De Roo L, Salomón R L, Steppe K. Woody tissue photosynthesis reduces stem $\mathrm{CO}_{2}$ efflux by half and remains unaffected by drought stress in young Populus tremula trees. Plant, Cell \& Environment, 2020, 43(4) : 981-991.

[ 4 ] Ávila E, Herrera A, Tezara W. Contribution of stem $\mathrm{CO}_{2}$ fixation to whole-plant carbon balance in nonsucculent species. Photosynthetica, 2014 , 52 (1) : 3-15.

[ 5 ] Nilsen E T, Rundel P W, Sharifi M R. Diurnal gas exchange characteristics of two stem photosynthesizing legumes in relation to the climate at two contrasting sites in the california desert. Flora, 1996, 191(2) : 105-116.

[ 6 ] Wittmann C, Pfanz H. More than just $\mathrm{CO}_{2}$-recycling: corticular photosynthesis as a mechanism to reduce the risk of an energy crisis induced by low oxygen. New Phytologist, 2018, 219(2): 551-564.

[ 7 ] Wittmann C, Pfanz H. Antitranspirant functions of stem periderms and their influence on corticular photosynthesis under drought stress. Trees, $2008,22(2): 187-196$.

[ 8 ] Cernusak L A, Cheesman A W. The benefits of recycling: How photosynthetic bark can increase drought tolerance. New Phytologist, 2015, 208 (4) : 995-997.

[ 9 ] Kocurek M, Kornas A, Wierzchnicki R, Luttge U, Miszalski Z. Importance of stem photosynthesis in plant carbon allocation of Clusia minor. Trees, 2020, 34(4): 1009-1020.

[10] De Roo L, Salomón R L, Oleksyn J, Steppe K. Woody tissue photosynthesis delays drought stress in Populus tremula trees and maintains starch reserves in branch xylem tissues. New Phytologist, 2020, 228(1): 70-81.

[11] Bloemen J, Vergeynst L L, Overlaet-Michiels L, Steppe K. How important is woody tissue photosynthesis in poplar during drought stress? Trees, $2016,30(1): 63-72$.

[12] Liu J X, Gu L, Yu Y C, Huang P, Wu Z G, Zhang Q, Qian Y Q, Wan X C, Sun Z Y. Corticular photosynthesis drives bark water uptake to refill embolized vessels in dehydrated branches of Salix matsudana. Plant, Cell \& Environment, 2019, 42(9) : $2584-2596$.

[13] Bloemen J, Overlaet-Michiels L, Steppe K. Understanding plant responses to drought: How important is woody tissue photosynthesis? Acta Horticulturae, 2019, 991(991): 149-155.

[14] Allen C D, Macalady A K, Chenchouni H, Bachelet D, McDowell N, Vennetier M, Kitzberger T, Rigling A, Breshears D D, Hogg E H, Gonzalez P, Fensham R, Zhang Z, Castro J, Demidova N, Lim J H, Allard G, Running S W, Semerci A, Cobb N. A global overview of drought and heat-induced tree mortality reveals emerging climate change risks for forests. Forest Ecology and Management, 2010, 259 (4) : 660-684.

[15] Mitchell P J, O' Grady A P, Tissue D T, White D A, Ottenschlaeger M L, Pinkard E A. Drought response strategies define the relative contributions of hydraulic dysfunction and carbohydrate depletion during tree mortality. New Phytologist, 2013,197 (3) : 862-872.

[16] Rodríguez-Calcerrada J, Martin-StPaul N K, Lempereur M, Ourcival J M, Del Rey M D C, Joffre R, Rambal S. Stem CO 2 efflux and its contribution to ecosystem $\mathrm{CO}_{2}$ efflux decrease with drought in a Mediterranean forest stand. Agricultural and Forest Meteorology, 2014, 195-196: $61-72$.

[17] Vandegehuchte M W, Bloemen J, Vergeynst L L, Steppe K. Woody tissue photosynthesis in trees: Salve on the wounds of drought? New Phytologist, 2015, 208(4): 998-1002.

[18] Cernusak L A, Marshall J D. Photosynthetic refixation in branches of Western White Pine. Functional Ecology, 2000, 14(3) : 300-311.

[19] Wittmann C, Matyssek R, Pfanz H, Humar M. Effects of ozone impact on the gas exchange and chlorophyll fluorescence of juvenile birch stems (Betula pendula Roth.). Environmental Pollution, 2007, 150(2) : 258-266.

[20] 刘俊祥, 于永畅, 郎蓬蓬, 沈豪, 巨关升, 孙振元. 旱柳枝条皮层叶绿体的光化学特性及结构的特化. 林业科学, 2018, 54(5): 30-35.

[21] 王文杰, 祖元刚, 王慧梅. 林木非同化器官树枝 (干) 光合功能研究进展. 生态学报, 2007, 27 (4) : 1583-1595.

[22] 蔡锡安, 曾小平, 陈远其. 树干皮层光合作用一一生理生态功能和测定方法. 生态学报, 2015, 35(21)：6909-6922.

[23] 陈昌笃, 张立运, 胡文康. 古尔班通古特沙漠的沙地植物群落、区系及其分布的基本特征. 植物生态学与地植物学丛刊, 1983, 7(2): 89-99.

[24] 李从娟, 马健, 李彦, 李惠. 梭梭和白梭梭主根周围土壤养分的梯度分布. 中国沙漠, 2011, 31(5): 1174-1180.

[25] 严巧娣, 苏培尔, 陈宏涁, 张岭梅. 五种 $\mathrm{C}_{4}$ 荒漠植物光合器官中含晶细胞的比较分析. 植物生态学报, 2008, 32(4) : 873-882. 
[26] 刘乾. 古尔班通古特沙漠南缘植物群落多样性与植被覆盖变化分析 [D ]. 乌鲁木齐: 新疆农业大学, 2009.

[27] Chang T G, Song Q F, Zhao H L, Chang S Q, Xin C P, Qu M N, Zhu X G. An in situ approach to characterizing photosynthetic gas exchange of rice panicle. Plant Methods, 2020, 16(1): 92.

[28] 叶子飘. 光合作用对光和 $\mathrm{CO}_{2}$ 响应模型的研究进展. 植物生态学报, 2010, 34(6): 727-740.

［29］管博, 于君宝, 陆兆华, 张莹, 王雪宏. 黄河三角洲滨海湿地水盐胁迫对盐地碱蓬幼苗生长和抗氧化酶活性的影响. 环境科学, 2011, 32 (8) : 2422-2429.

[30］王莹. 叶片与树枝绿色组织 $\mathrm{C}_{4}$ 酶活性、色素含量、叶绿素菼光特征及光谱特征的差异 $[\mathrm{D}]$. 哈尔滨: 东北林业大学, 2011.

[31] Levizou E, Manetas Y. Photosynthetic pigment contents in twigs of 24 woody species assessed by in vivo reflectance spectroscopy indicate low chlorophyll levels but high carotenoid/chlorophyll ratios. Environmental and Experimental Botany, 2007, 59(3) : 293-298.

[32] Wittmann C, Aschan G, Pfanz H. Leaf and twig photosynthesis of young beech (Fagus sylvatica) and aspen (Populus tremula) trees grown under different light regime. Basic and Applied Ecology, 2001, 2(2) : 145-154.

[33] Meir P, Shenkin A, Disney M, Rowland L, Malhi Y, Herold M, Da Costa A C L. Plant structure-function relationships and woody tissue respiration: upscaling to forests from laser-derived measurements//Tcherkez G, Ghashghaie J, eds. Plant Respiration: Metabolic Fluxes and Carbon Balance. Cham: Springer, 2017: 89-105.

[34] Hölttä T, Kolari P. Interpretation of stem $\mathrm{CO}_{2}$ efflux measurements. Tree Physiology, 2009, 29(11) : $1447-1456$.

[35] Salomón R L, Steppe K, Crous K Y, Noh N J, Ellsworth D S. Elevated $\mathrm{CO}_{2}$ does not affect stem $\mathrm{CO}_{2}$ efflux nor stem respiration in a dry Eucalyptus woodland, but it shifts the vertical gradient in xylem $\left[\mathrm{CO}_{2}\right]$. Plant, Cell \& Environment, 2019, 42(7): 2151-2164.

[36] Kunstler G, Falster D, Coomes D A, Hui F, Kooyman R M, Laughlin D C, Poorter L, Vanderwel M, Vieilledent G, Wright S J, Aiba M, Baraloto C, Caspersen J, Cornelissen J H C, Gourlet-Fleury S, Hanewinkel M, Herault B, Kattge J, Kurokawa H, Onoda Y, Peñuelas J, Poorter H, Uriarte M, Richardson S, Ruiz-Benito P, Sun I F, Ståhl G, Swenson N G, Thompson J, Westerlund B, Wirth C, Zavala M A, Zeng H C, Zimmerman J K, Zimmermann N E, Westoby M. Plant functional traits have globally consistent effects on competition. Nature, 2015, 529(7585) : 204-207.

[37] Salomón R, Valbuena-Carabaña M, Teskey R, McGuire M A, Aubrey D, González-Doncel I, Gil L, Rodríguez-Calcerrada J. Seasonal and diel variation in xylem $\mathrm{CO}_{2}$ concentration and sap pH in sub-Mediterranean oak stems. Journal of Experimental Botany, 2016, 67(9) : $2817-2827$.

[38] Nilsen E T. The influence of water stress on leaf and stem photosynthesis in spartium junceum L. Plant, Cell \& Environment, 1992, 15 (4) : 455-461.

[39] Sevanto S, McDowell N G, Dickman L T, Pangle R, Pockman, W T. How do trees die? A test of the hydraulic failure and carbon starvation hypotheses. Plant, Cell \& Environment, 2014, 37(1): 153-161.

[40] Wittmann C, Pfanz H, Loreto F, Centritto M, Pietrini F, Alessio G. Stem $\mathrm{CO}_{2}$ release under illumination: corticular photosynthesis, photorespiration or inhibition of mitochondrial respiration? Plant, Cell \& Environment, 2006, 29(6) : 1149-1158.

[41] Salomón R L, De Roo L, Bodé S, Boeckx P, Steppe K. Isotope ratio laser spectroscopy to disentangle xylem-transported from locally respired CO 2 in stem $\mathrm{CO}_{2}$ efflux. Tree Physiology, 2019, 39(5): 819-830.

[42] Ávila-Lovera E, Zerpa A J, Santiago L S. Stem photosynthesis and hydraulics are coordinated in desert plant species. New Phytologist, 2017,216 (4) : 1119-1129.

[43] Simkin A J, Faralli M, Ramamoorthy S, Lawson T. Photosynthesis in non-foliar tissues: implications for yield. The Plant Journal, 2020, 101 (4) : 1001-1015. 